Estudios Constitucionales, Año 10, No 1, 2012, pp. 481 - 486.

ISSN 0718-0195

Centro de Estudios Constitucionales de Chile Universidad de Talca

"Comentario al libro 'nuevas perspectiva en derecho público"”

Tomás Jordán Díaz

\title{
COMENTARIO AL LIBRO "NUEVAS PERSPECTIVAS EN DERECHO PÚBLICO”
}

Editoral LibroteCNia, 2011, 658 PP.

TOMÁs JoRdÁn DÍAZ

Lo más difícil en una disciplina científica es avanzar en la generación de conocimiento, pues muchas veces parecen ser más las razones para continuar una academia de administración que de formulación de nuevas ideas. La ciencia jurídica tiene muchas virtudes, pero un gran defecto, y es que tiende a ser un área de conocimiento descriptivo más que crítico o propositivo. Los viejos libros de derecho constitucional se nos muestran como reflejos de una sociedad escasamente cambiante, donde los procesos socio-culturales no necesariamente coinciden con la norma fundamental y la aplicación de ésta.

La renovación generacional y disciplinar es la clave del libro "Nuevas perspectivas en Derecho Público", en el cual un grupo de jóvenes académicos, liderados por el profesor Núñez Leiva y patrocinado por la Universidad Andrés Bello, ambos de Chile, se comprometen firmemente en la construcción de una mirada innovadora del derecho público iberoamericano, sumando un examen sobre Alemania como invitado siempre bienvenido. Sus autores se muestran respetuosos de la tradición académica, pero van más allá de ella. Pretenden observar y analizar la Constitución, realizando una aproximación de crítica científica, haciendo hincapié en los defectos, correcciones y complementaciones que son necesarios. Lo curioso es que es una mirada compartida por los autores, por lo que podemos afirmar que el espíritu examinador es un común denominador en las nuevas generaciones de investigadores del derecho constitucional.

${ }^{1}$ Licenciado en Ciencias Jurídicas y Sociales, Universidad de Chile. Abogado. Magíster en Ciencia Política, Universidad de Chile. Diploma en Estudios Especializados en Derecho Público y Diploma en Estudios Avanzados, Universidad Autónoma de Barcelona. Magíster en Derecho Público, mención Derecho Constitucional, Universidad Autónoma de Barcelona. Director del Centro de Derecho y Justicia (CDJ) de la Escuela de Derecho de la Universidad Católica Silva Henríquez. Profesor de Derecho Constitucional en la Universidad Católica Silva Henríquez y en la Universidad Alberto Hurtado. Abogado de Vial \& Asociados. tjordan@ucsh.cl. 
Hay elementos que son ejes en la nueva mirada del derecho público: la democracia, la dogmática constitucional, los derechos fundamentales, los tratados internacionales y la institucionalidad.

Nuestras democracias latinoamericanas siempre están siendo objeto de enjuiciamientos, requiriendo de revisiones que la profundicen, y es así que Riberi nos propone un modelo "democrático representativo de base republicana y democrática" guiado por el "constitucionalismo popular" de base norteamericana "(...) donde el poder constituyente precisa por lo tanto el rostro del "demos" para que la autoridad creada tenga su respaldo", y en el caso chileno, Silva Alliende afirma la urgencia de reformular las bases democráticas, pues "(...) la democracia en Chile sólo puede consolidarse con una transformación constitucional que deje atrás el proyecto pinochetista y logre asentar un liderazgo democrático en el Congreso y el Tribunal Constitucional's; pero esta democracia debe ir ligada a una institucionalidad sólida que permita avanzar hacia un desarrollo económico y social, tal como "una visión finalista del constitucionalismo lo exige", sostiene Zuloaga Gil.

Ahora bien, ello sólo es posible en el marco de un Estado democrático de Derecho, que no puede funcionar sin una justicia constitucional, donde los contenidos y principios lógicos de la Constitución, siguiendo a Hennig Leal, "no pueden ser realizados sin la actuación destacada de la jurisdicción"s, que para Tortora Aravena se ordena como "aquella función del Estado de origen constitucional cuyo objetivo es conocer y resolver los conflictos de relevancia jurídica entre partes, en forma pacifica por los Tribunales de Justicia establecidos por la ley (...) a través de una sentencia que ha sido dictada como consecuencia de un proceso previo y con valor de cosa juzgada (...)". La Constitución nos debe otorgar seguridad sostiene Acevedo Miño, y "es claro que la cultura de la legalidad debe manifestarse, en primer lugar, en el comportamiento de los poderes públicos. Así, el Estado no solamente no ha de actuar contar legem, sino que, únicamente ha de actuar secundum legem".

Este actuar de conformidad a la Constitución y a la ley nos lleva a cuestionar varios asuntos, como por ejemplo lo hace Gamarra Pérez sobre la omisión legislativa. Sostiene que la Constitución está para ser cumplida, de modo que "el Legislador tiene la obligación de ejecutar las disposiciones constitucionales y en consecuencia es responsable

${ }^{2}$ Pp. 122 y 125.

${ }^{3}$ P. 36.

${ }^{4}$ P. 62.

${ }^{5}$ P. 462.

${ }^{6}$ P. 47. 
de las omisiones en las que incurra ya que una norma constitucional omitida implica la posibilidad de hacerla valer como norma". Núñez Leiva realiza un trabajo vinculativo entre el legislador y su responsabilidad por la generación de normas inconstitucionales, afirmando la responsabilidad patrimonial del Estado legislador por los perjuicios que pueden ocasionar una norma contraria a la Constitución. El autor nos dice que "en este contexto, la única alternativa que existiría para reparar los perjuicios derivados de la aplicación de una ley declarada inconstitucional, sería la reclamación de indemnización por hechos del legislador'8. Por su parte, y en lo referente a la relación Constitución-ley, se explora la naturaleza de la norma de reforma constitucional, la cual, de acuerdo a Henríquez Viñas, tiene una naturaleza "constitucional y no legal" ya que "está involucrado el poder de reforma, cuya entidad y voluntad es distinto y superior al poder legislativo que interviene en la dictación de la ley" donde su validez depende de "su adecuación a la Norma sobre la Reforma".

Toda aproximación a los derechos fundamentales conlleva la visualización de distintas miradas de éstos. Partimos de la base, y como plantea Marciani Burgos, que los derechos "resultan indispensables para realizar cualquier proyecto de vida que-usando las palabras de Gray- "merezca la pena ser vivida"lo. En este contexto, algunos, como por ejemplo Aponte Nuñez, sostiene la tesis de los derechos implícitos fundado en el modelo constitucional venezolano, donde el Estado están compelido a "garantizar el ejercicio y disfrute de los mismos con independencia de su reconocimiento expreso por una norma de derecho constitucional, con lo cual se puede afirmar que existen derechos con o y sin normas "11; pero en cambio, Contreras Vázquez sostiene la necesidad de superar el "problema de los derechos implícitos", debiendo recomprenderlos con base a dos elementos: las normas positivas de derecho fundamental y en relación a las potestades constitucionales de los órganos del Estado. Enuncia que el legislador y el Tribunal Constitucional son titulares de potestades que les permiten actualizar y concretar los enunciados de derecho fundamental, por lo que "la actualización y la concreción parecen mecanismos más que suficientes para tutelar la igualdad y la libertad en nuestro sistema constitucional, sin tener que recurrir a elucubraciones teóricas sobre derecho no enumerados, no enunciados o, simplemente, implícitos" 12 .

${ }^{7}$ P. 445.

${ }^{8}$ Pp. 417 y 418.

${ }^{9}$ Pp. 88 y 89.

${ }^{10}$ Pp. 300 y 301.

${ }^{11}$ Pp. 217 y 218.

${ }^{12}$ Pp. 182 y 183. 
El libro nos abre a los nuevos temas de derechos fundamentales que son objeto de estudio y de exigencia, tales como los derechos de las personas del mismo sexo, la objeción de conciencia, el derecho de acceso a la información pública, los derechos sociales y la pobreza como categoría genérica de vulneración de los derechos humanos. Vidal Beros investiga los derechos de las parejas del mismo sexo, y el derecho a formar una familia, aseverando que su no regulación conlleva "una responsabilidad por omisión del Estado chileno, en virtud de las normas internacionales a las cuales se encuentra comprometido" donde la diferenciación por sexos carece de sostén, indicando que "nuestra legislación es contradictoria y carece de fundamentos reales al momento de exigir la heterosexualidad para contraer matrimonio". La objeción de conciencia, afirmada como un derecho implícito por Díaz Toloza, obliga al juez a decidir "considerando preferentemente los siguientes parámetros: 1. Los límites de la libertad de conciencia y de las manifestaciones de ella, y 2. La legalidad y justicia del deber jurídico impuesto por la norma o la autoridad"13.

El derecho de acceso a la información pública ubica como titular a las personas frente a los órganos del Estado, pero en su ejercicio puede verse afectado el derecho a la vida privada de las propias personas que trabajan en la Administración, debiendo ponderar los bienes jurídicos en la cual se equilibren, a juicio de Salinas Muñoz, "las circunstancias concretas que efectiva y claramente permitan arribar a la conclusión de que existe un interés y un beneficio de la sociedad en contar con dicha información, pues de lo contrario deberá negarse el acceso a ella, en pos del derecho que potencialmente se vería conculcado"'4.

Los autores plantean que dentro de las complejidades de realización efectiva de los derechos, en particular de los derechos sociales, es que en América Latina no se encuentra dadas las condiciones. López Daza da cuenta de esta crítica y afirma la necesidad que los jueces enfaticen las medidas de protección de estos derechos, aunque "esta posición de los jueces ha llevado a confrontaciones con el sector político que no ve con buenos ojos la "interferencia" por parte de funcionarios de otro poder en los asuntos que eran exclusivamente los poderes ejecutivo y legislativo. Sin embargo la tarea protectora debe continuar "'5: Así, la pobreza se nos presenta como una violación de los derechos humanos, implicando, sostiene Guiñazú "obligaciones de respeto, de garantía, de adoptar medidas legislativas - o de otro carácter-y la prohibición de discriminación, se intensifican y particularizan ante la pobreza y los pobres". ${ }^{16}$

${ }^{13}$ Pp. 249 y 250.

${ }^{14}$ P. 338.

${ }^{15}$ P. 367.

${ }^{16}$ P. 390. 
Las obligaciones de cumplimiento no sólo provienen del sistema jurídico interno, sino también del internacional, reconociendo que hay una distancia entre obligaciones internacionales y cumplimiento de éstas. Benavides Casals afirma que "Esto se refleja en las múltiples ratificaciones de los tratados pero en las permanentes acusaciones de incumplimiento de los tratados por no aplicación de ellos en el ámbito doméstico. Este incumplimiento parece una contradicción con las obligaciones asumidas por los estados al manifestar su voluntad en el ámbito internacional de vincularse a los tratados" $;{ }^{17}$ donde la no incorporación de la evolución de las nuevas generaciones de derechos humanos, como señala Amoza Antúnez de Oliveira sobre el sistema constitucional uruguayo, "son susceptibles de condena por parte de la Corte Interamericana de Derechos Humanos, en razón de ser contrarias a las garantías del debido proceso sustantivo consagradas en los Tratados Internacionales a que el Estado uruguayo ha adherido". ${ }^{18}$

Finalmente, hay una revisión de la nueva institucionalidad, de los modelos federales y autonómicos de Estado. En el caso chileno, y concluyendo el libro, Andrea Lucas Garín sostiene que la nueva institucionalidad ambiental permitirá una mejor gestión de los riesgos, donde el desarrollo sostenible exige "gobernanza ambiental, en que se concilien objetivos de conservación con desarrollo socioeconómico adecuado (...) La necesidad de acción por parte del Estado es ineludible"19. López Portas visualiza la reforma estatutaria como el principal instrumento jurídico "que ha marcado el comienzo de una nueva etapa en el desarrollo del Estado autonómico español caracterizada por el incremento del poder regional impulsado por las propias comunidades autónomas" ${ }^{20}$; y Hestermeyer expresa que la cláusula de homogeneidad no sólo abarca la invocación de los "valores comunes de los miembros de un sistema" sino que también debe estar sujeta "al control por parte de los órganos jurisdiccionales y quizá contar con el reforzamiento de mecanismos de implementación y sanciones concretas para los casos de su violación. Los principios incluidos en la cláusula de homogeneidad -como republicanismo o democraciapermiten un margen de interpretación y el reproche de violar dichos principios es percibido como extremadamente grave ${ }^{321}$.

En síntesis, estamos en presencia de un libro imprescindible para aproximarnos a los nuevos temas del derecho público y a la investigación de una generación de

${ }^{17}$ P. 500.

${ }^{18}$ P. 528.

${ }^{19}$ P. 647.

${ }^{20}$ Pp. 557 y 558.

${ }^{21}$ P. 589. 
académicos que ya están emplazados en diversas universidades de iberoamérica, con un alto estándar científico y que necesariamente serán los que orienten la discusión académica en los próximos años. 